\title{
NAZISMO, FASCISMO, INTEGRALISMO E O APOIO \\ DAS OLIGARQUIAS DO RIO GRANDE DO SUL E DE SANTA CATARINA AO ESTADO NOVO
}

René E. Gertz*

"Estou convencido de que o perfil do sul do continente seria outro se a Alemanha tivesse vencido a guerra de 1939. Hitler teria realizado seu velho sonho de domínio do mundo, formando aqui sua Alemanha Austral, na região mais rica e mais povoada de alemães. Essa base cultural e étnica comum favorecia o separatismo do sul do Brasil."."

Esta afirmação de Cordeiro de Farias reflete uma convicção que certamente era a de muitos políticos ligados a Vargas. E ela representa para muitos deles, incluindo provavelmente o próprio, uma situação de ambivalência: por um lado simpatizavam com o regime nazista na Alemanha ou ao menos tinham interesse num bom relacionamento diplomático e comercial com este país, mas por outro lado temiam os "alemães" do sul do Brasil e sabiam que medidas contra eles inevitavelmente afetariam as relaçōes Brasil-Alemanha.

Cordeiro de Farias diz pouco adiante que declarou sua guerra "contra a Alemanha em fins de 1938, antes portanto do início da Segunda Guerra Mundial". ${ }^{2}$ Na verdade a guerra aos "alemães" e a outros grupos étnicos foi declarada bem antes. Se examinarmos as leis destinadas a regulamentar a vida dos estrangeiros no Brasil, e que no sul visavam sobretudo alem̃es e italianos, vemos que grande parte delas é de início de $1938 .^{3}$ São portanto anteriores à intentona integralista e não podem ter sido motivadas por este episódio. Desta forma é de presumir que a campanha contra os "estrangeiros" alemães e italianos não decorreu de uma decisão repentina motivada por uma possível participação estrangeira ou de "minorias étnicas" no atentado a Vargas em maio de 1938. 
$\mathrm{Na}$ verdade muitos autores apresentam o temor em relação às regiōes de colonização estrangeira como um dos fatores que levaram à decretação do Estado Novo. John Wirth ao fazer um arrolamento das razões para a implantação deste regime cita, entre outros, motivos militares, que seriam dois: a rivalidade com a Argentina e as colônias estrangeiras no sul do país. ${ }^{4}$ Mais recentemente Ricardo Seitenfus afirma que, "apesar de não ser sequer mencionado no programa governamental", a questão das minorias étnicas é um problema-chave para o novo governo, que com seu ideal de “"'coesão nacional' não pode tolerar a existência de núcleos mal integrados". 5

Parece que muitos políticos da esfera federal tinham efetivamente medo de que as regiбes coloniais do sul do Brasil viessem a representar um perigo para a unidade, integridade e governabilidade do país. E havia indicios que fundamentavam este temor. Ao menos no que tange às regiôes de colonização alemã havia desde longa data os ideólogos do germanismo, que defendiam a não-assimilação de alemães e descendentes como programa. Mais recentemente tinham sido fundados núcleos do partido nazista alemão nestas regiões e o integralismo era mais forte do que nas demais regióes dos estados do sul, chegando em Santa Catarina a conquistar a maioria das prefeituras do vale do Itajaí nas eleições municipais de março de 1936.

Pessoalmente julgo que este perigo de fato não foi significativo. Não há nenhum indício sério de que a Alemanha nazista perseguisse objetivos político-militares no sul do Brasil e nunca qualquer tentativa de arregimentação étnica teve sucesso; nunca houve também qualquer articulação séria com base étnica para enfrentar os governos regionais e muito menos o governo central. Mas não pretendo aprofundar este assunto neste momento. Pretendo concentrar-me num outro aspecto da questão e sugerir que aquilo que efetivamente estava acontecendo nas regiбes coloniais e/ou aquilo que se supunha ou dizia estar acontecendo interessava muito às oligarquias tradicionais do Rio Grande do Sul e de Santa Catarina na medida em que contribura para a desarticulação do regime constitucional vigente $\mathrm{e}$ a conseqüente possibilidade de manutenção do poder destas oligarquias.

Comprovar esta hipótese para o caso do Rio Grande do Sul ainda exigirá muita pesquisa, mas pretendo apresentar alguns dados que sugerem que na década de 1930 chegamos a um "clímax" no confronto surdo entre o Rio Grande do Sul tradicional e o Rio Grande do Sul moderno, e isto significa: entre o Rio Grande do Sul predominantemente luso-brasileiro, agrário-latifundista e o Rio Grande do Sul de origem imigrante, baseado na pequena propriedade agrária, no artesanato e na indústria .

Nunca houve um confronto aberto entre estas regiøes e é por isso 
Nazismo, Fascismo, In tegralismo e o apoio das oligarquias ...

que apesar de as colônias do Rio Grande do Sul não serem, objetivamente, menos "quisto étnico" do que as de Santa Catarina, são estas últimas que tradicionalmente são apresentadas como tais, justamente porque neste estado o confronto é mais claro e aberto, como ainda veremos.

Provavelmente o confronto no Rio Grande do Sul nunca chegou a ser explícito por várias razões. Primeiramente as regiões coloniais têm uma evolução econômica mais lenta e sua evolução demográfica é neutralizada pelo avanço da colonização sobre áreas virgens, onde são deslocados índios, mas as regióes tradicionais não são afetadas por esta expansão. Em segundo lugar a evolução econômica das regióes coloniais não foi de tal ordem que ocorresse um desequilíbrio, ou seja, que as regiôes coloniais adquirissem um peso econômico muito superior às regiões tradicionais. Em terceiro lugar o castilhismo, cuja continuidade sob este aspecto podemos seguir até Flores da Cunha, soube neutralizar muito bem a ascensão política das regiōes coloniais. Através de um pacto tácito, que incluía uma série de concessőes, os governos de Júlio de Castilhos até Flores da Cunha conseguiram manter uma certa quietude política nas regiões coloniais, evitando a ascensão de políticos provenientes das mesmas.

Mas na década de 1930 este esquema parece chegar a um esgotamento. Faltam estudos minuciosos que comprovem este fato de uma maneira mais concreta, mas pretendo apresentar alguns dados que sugerem a correção desta hipótese. Devemos ser cautelosos na utilização de determinados dados estatísticos. De qualquer forma - e ciente dos riscos - construí um quadro no qual é feito um levantamento dos nomes alemães e italianos na assembléia legislativa gaúcha. Apesar de saber que a origem étnica do nome não oferece uma informação inequívoca sobre que setor da sociedade ou que região o deputado representa e apesar de conhecer a enorme diferença que há entre a assembléia de representantes da República Velha e a assembléia legislativa pós-1945 como locus de representação da sociedade, os números parecem significativos.

Pelo Quadro I vê-se que desde o início da República até 1935 há, após um crescendo inicial, uma estabilização em torno de $15 \%$ dos deputados com nomes alemães e italianos. Se formos verificar o que acontece após 1945, vemos que em $194741,8 \%$ dos deputados da assembléia legislativa têm nomes alemães ou italianos e em 1950 são $35 \%$.

Um outro dado, menos expressivo, mas interessante: um autor muito bem informado sobre a presença alemã no estado contou que em 193012 de um total de 80 prefeitos tinham nomes alemães e que em 1938 este número crescera para 17 entre 86 , aumentando, portanto, de $15 \%$ para $19,7 \% .^{6}$ 


\section{Quadro I}

Presença de nomes italianos e alemães no poder legislativo do Rio Grande do Sul (1891-1950)

\begin{tabular}{c|c|c|c|c}
\hline Ano & $\begin{array}{c}\text { Total } \\
\text { deputados }\end{array}$ & $\begin{array}{c}\text { Total de } \\
\text { nomes alemães }\end{array}$ & $\begin{array}{c}\text { Total de } \\
\text { nomes italianos }\end{array}$ & $\begin{array}{c}\text { Percentual de } \\
\text { nomes estrangeiros }\end{array}$ \\
\hline 1891 & 43 & 3 & 0 & 6,9 \\
1892 & 32 & 3 & 0 & 9,3 \\
1897 & 29 & 3 & 1 & 13,7 \\
1901 & 31 & 3 & 1 & 12,9 \\
1905 & 38 & 3 & 2 & 13,1 \\
1909 & 35 & 3 & 1 & 11,4 \\
1913 & 33 & 4 & 1 & 15,1 \\
1917 & 32 & 5 & 1 & 18,7 \\
1921 & 33 & 6 & 0 & 18,1 \\
1925 & 32 & 4 & 1 & 15,6 \\
1929 & 32 & 3 & 1 & 12,5 \\
1935 & 36 & 5 & 1 & 16,6 \\
1947 & 55 & 16 & 7 & 41,8 \\
1950 & 56 & 13 & 7 & 35,7 \\
\hline
\end{tabular}

Fonte: Trindade, Hélgio. Poder Legislativo e autoritarismo no Rio Grande do Sul, 1891-1937. Porto Alegre, Sulina, 1980, pp. 289-297 e 373374 (para os anos 1891 a 1935); Roche, Jean. A colonização alemã e o Rio Grande do Sul. Porto Alegre, Globo, 1969, p. 764 (para os anos 1947 a 1950).

Estes dados sugerem que no período de que estamos tratando há um deslocamento do eixo político do Rio Grande do Sul e se não chegou a tanto, houve ao menos um crescimento significativo da presença das regiбes coloniais no cenário político gaúcho. Talvez isto explique em parte a verdadeira bajulação de Flores da Cunha em relação às populaçбes coloniais, numa tentativa extrema de coopotação.

Para continuar por algumas linhas com o jogo de números, montei outro teste, desta vez para verificar a importância demográfica e econômica da região colonial frente à regiáo tradicional. Para tanto dividi o Rio Grande do Sul em duas partes através de uma linha que vai de São Borja 
Nazismo, Fascismo, Integralismo e o apoio das oligarquias . . .

a Osório. Naturalmente esta divisão tem um quê de arbitrário, pois a parte norte inclui regiбes tradicionais, como Vacaria, e a parte sul inclui regióes que podem ser consideradas de imigração, como grande parte do município de Cachoeira do Sul e a região claramente colonial em torno de São Lourenço do Sul. De qualquer forma, a parte sul engloba aproximadamente a metade mais tradicional $\left(150.310 \mathrm{~km}^{2}\right)$ e a metade norte a parte predominantemente colonial $\left(121.458 \mathrm{~km}^{2}\right)$. Demograficamente a metade sul tinha em 1920856.200 e a metade norte 931.668 habitantes. Em 1940 a parte sul tem 1.203 .026 e a parte norte 1.845 .371 habitantes. $^{7}$ Isto significa que já em 1920 a metade norte, apesar de menor, superava a sul numa proporção de $1: 1,08$, mas até 1940 esta proporção se ampliara significativamente, passando para 1:1,53.

Caberia também uma comparação diacrônica mais minuciosa sobre a importância econômica das duas regióes. Mas enquanto esta investigação não existe, restrinjo-me a apresentar dados relativos às atividades classificadas como industriais na segunda metade da década de 1930. Segundo a Estatistica Industrial do Rio Grande do Sul relativa a 1937 temos que na região sul estavam cadastrados 18.523 operários ativos em trabalhos industriais, enquanto na região norte havia 22.741. Se formos comparar o valor da produção industrial temos que o sul produzia 489.926 .000 e o norte 446.950 .000 \$. $^{8}$

Todos estes dados sugerem o "crescimento" da região colonial frente à região tradicional e a conseqüente "diminuiçđ̃o" relativa desta última. Eles tornam plausível a hipótese de que as forças políticas das regiôes tradicionais aproveitassem a existência de movimentos estrangeiros e radicais na região colonial para fomentar o medo do governo federal e obter uma intervenção nas "colônias", intervenção que seria concretizada pela ação "nacionalizadora" de um governo central fortalecido.

Mas se no caso do Rio Grande do Sul somos obrigados a restringirnos a algumas evidências que tornam a hipótese apenas plausível, pode-se chegar a uma demonstração quase definitiva em Santa Catarina.

Neste estado a coexistência das regiōes tradicionais com as regiōes coloniais há muito tempo evoluía de uma forma bastante diferente da do Rio Grande do Sul. Se pensarmos em termos de representação política na assembléia estadual catarinense, veremos que de 1898 até 1930 a representação percentual de deputados com nomes alemães sempre correspondeu ao percentual de população teuta no estado, ou seja, neste período $19,4 \%$ dos mandatos foram exercidos por deputados de nome alemão. ${ }^{9}$

Se formos contar os nomes dos prefeitos do estado veremos que em 1935 de um total de 40 chefes de executivo municipal 14 tinham nomes alemaes, o que representa um percentual de $35 \%,{ }^{10}$ 
Mas em Santa Catarina não é necessário ater-se tão rigidamente aos dados numéricos para comprovar a presença maciça das regióes coloniais na estrutura estadual de poder. No triunvirato que constituiu o primeiro governo estadual após a queda da Monarquia estava Raulino Júlio Adolpho Horn. Logo depois aparece Lauro Müller que juntamente com Felipe Schmidt vai dominar a política estadual por muito tempo. Mesmo que apareça neste período um governador de nome Hercílio Luz, sua base política é Blumenau. O trio Müller/Schmidt/Luz perde o governo do estado de 1910 a 1914 para Vidal Ramos, um típico representante da oligarquia tradicional agrária, mas o reconquista nesta última data, dominando o estado até o início da década de 1920, quando começam a despontar os irmãos Konder (Adolpho, Marcos e Victor). Adolpho é secretário das finanças de Hercílio Luz em 1918, deputado federal em 1921 e governador de 1926 em diante. Victor é deputado estadual em 1919, substitui seu irmão na secretaria das finanças e chega a ministro dos transportes de Washington Luís em 1926. Marcos foi deputado estadual desde 1913.

Demograficamente a região representada por estes políticos compreendia apenas algo em torno de $20 \%$ da população total do estado.

Do ponto de vista econômico faltam-me também aqui indicadores referentes à década de 1920 para uma melhor comparação diacrônica, mas Carlos Henrique Oberacker cita um cálculo de Marcos Konder segundo o qual os 10 principais municípios coloniais do vale do Itajaí, onde residiam os citados $20 \%$ da população catarinense, contribuíam em 1935 com $82 \%$ dos impostos de consumo arrecadados pela União no estado, $61,25 \%$ dos impostos de renda, $67 \%$ dos impostos sobre vendas. ${ }^{11}$ Mesmo que estes dados devam ser tratados com cuidado, justamente por terem sido fornecidos por Marcos Konder, o relatório oficial de 1935 do governador Nereu Ramos mostra que naquele ano $38,7 \%$ dos impostos municipais provieram dos munić́pios citados por Konder. ${ }^{12}$ Em $193634,8 \%$ dos impostos fixos arrecadados pela União provieram da mesma área. ${ }^{13}$

Temos portanto em Santa Catarina uma polarização clara entre regiōes tradicionais, cujo centro é Lages e onde domina a famılia Ramos, e as regiōes de imigração do vale do Itajaí. Ao contrário do Rio Grande do Sul, as regiôes coloniais tomam a dianteira muito cedo, como vimos pela sucessão do domínio político no estado. Mas aŕ vem a crise de 1930. Os Konder estão comprometidos com Washington Luís e Júlio Prestes, os Ramos resolvem apostar em Vargas e isto lhes possibilita o retorno ao poder após longa ausência. Depois de um curto período de governo militar logo após a campanha revolucionária de 1930 assume Aristiliano Ramos, tio de Nereu Ramos, o líder da campanha de Vargas no estado. 
Uma das primeiras medidas foi a assinatura de um decreto, alterando a sistemática de cobrança de impostos, onerando o capital e desonerando a propriedade agrária. Outro decreto visa as escolas privadas, muito difundidas nas regiōes coloniais, obrigando os professores das mesmas a prestar exames supervisionados pelo governo. Por fim foram desmembradas áreas para enfraquecer o município de Blumenau, criando-se o município de Rio do Sul.

Quando em 1933 se realizam as eleiçōes para a assembléia nacional constituinte o Partido Liberal Catarinense dos Ramos não obtém a quantidade de votos esperada na região do vale do Itajaí e por isso declaram guerra à região. Em fevereiro de 1934 desmembram Joinville, criando Jaraguá do Sul, e esfacelam Blumenau, criando quatro novos municípios. A região ficou em pé de guerra contra o governo estadual. O consul alemão de Florianópolis escreveu em um relatório da época que "a população urbana (de Blumenau) entrou numa espécie de greve geral", fechando-se as portas de bancos e casas comerciais. ${ }^{14}$ Um observador dos acontecimentos escreveu muitos anos depois: "O comércio e a indústria cerraram suas portas em sinal de protesto e durante mais de uma semana a cidade de Blumenau apresentou aspecto de verdadeira praça de guerra. Não fosse a prudência de algumas autoridades, o bom senso de alguns cidadãos mais avisados, o fato teria assumido proporções de verdadeiro desastre com o derramamento de sangue, que esteve iminente, pois o governo estadual já enviara força armada contra Blumenau e a população desta cidade se preparava para recebê-la a bala." 15

A partir deste momento o conflito entre a oligarquia Ramos e a região colonial se torna aberto e permanente. Não precisamos seguir todos os passos deste conflito. Em 1935, com a reconstitucionalização, é eleito governador do estado Nereu Ramos. Em 1 o de março de 1936 realizam-se as eleiçðes para os governos municipais e os integralistas vencem em todos os municípios do vale do Itajaí, com exceção de Brusque. Nereu Ramos tenta recuperar ao menos um pequeno espaço, desmembrando de Timbó o distrito de Rodeio, transformando-o em município. Neste distrito a população era predominantemente de origem italiana e Nereu Ramos supunha que ela lhe fosse mais fiel do que as populações das regiôes em que predominava a ascendência germânica. Mas ao convocar eleições neste novo município, também aqui seu candidato é derrotado por um candidato integralista de origem italiana como o candidato do governador.

A reação de Nereu Ramos a estes resultados eleitorais nos leva diretamente ao ponto em que queremos chegar. Em uma declaração prestada à imprensa o governador antecipa em quase dois anos seu apoio ao futuro Estado Novo. Indagado sobre os resultados das urnas, diz: "Quero explicar- 
lhes a vitória do integralismo, ou melhor, do hitlerismo. (...). Eu disse hitlerismo, porque ali o fenômeno do integralismo não se apresenta com as mesmas características que nos demais estados da federação. Em todos os municípios em que o integralismo venceu predomina o elemento alemão. A bandeira não é Plínio Salgado, mas sim Hitler. Quando se pergunta a um colono 'és integralista', ele responde 'sou hitlerista'. É a mística do militarismo alemão, como o caracterizou com muita propriedade o ministro Marques dos Reis". Em seguida Nereu Ramos aponta para a solução: "Creio que está na hora de se iniciar uma enérgica obra nacionalizadora nos municípios em que a colonização alemã não quer adaptar-se à vida brasileira (...). Isto significa: estacionar mais tropas nas zonas de imigração alemã, para que a mística do militarismo alemão tenha, em nossas casernas, um derivativo e os elementos teuto-brasileiros aprendam a integrar-se na vida brasileira."16

Esta declaração é tão clara que nã่o exige nenhuma exegese. Por isso podemos concluir: a bibliografia tem destacado a importância das atividades nazistas, fascistas e integralistas no sul do Brasil para a implantação do Estado Novo. No entanto esta bibliografia em geral destaca a realidade do perigo representado por estas atividades e por isso de alguma forma justifica as medidas implementadas pelo governo estadonovista. $\mathrm{O}$ que se propôs aqui é uma abordagem deste tema sob outro ângulo, perguntando quem pode ter sido beneficiado por estas atividades na medida em que elas desencadearam a ação governamental. Na verdade os acontecimentos foram aproveitados pelas oligarquias tradicionais do Rio Grande do Sul e de Santa Catarina para sustentar sua luta contra os grupos emergentes modernos das regiøes de colonização.

Caberia perguntar agora o que isto representou para a configuração da administração estadonovista nestes estados, mas este tema exige tratamento à parte.

\section{NOTAS}

${ }^{1}$ Camargo, Aspásia/Góes, Walder de. Meio século de combate: diálogo com Cordeiro de Farias. Rio de Janeiro, Editora Nova Fronteira, 1981, p. 272.

${ }^{2}$ Ibid., p. 273.

${ }^{3}$ Sobre estas leis e as respectivas datas cf. Carone, Edgard. O Estado Novo (1937. 1945). São Paulo, DIFEL, 1976, pp. 160-161. 
Nazismo, Fascismo, Integralismo e o apoio das oliga rquias ...

${ }^{4}$ Apud Levine, Robert (ed.). Brazil: fiel research guide in the social sciences. Columbia, Institute of Latin American Studies, 1966, p. 80.

${ }^{5}$ Seitenfus, Ricardo Antônio Silva. O Brasil de Getúlio Vargas. São Paulo, Companhia Editora Nacional, 1985, pp. 178 e 154, respectivamente.

${ }^{6}$ Respectivamente, Oberacker, Karlheinrich. Die volkspolitische Lage des Deutschtums in Rio Grande do Sul (Südbrasilien). Jena, Verlag von Gustav Fischer, 1936, p. 96 e Oberacker Jr., Karl H. Der deutsche Beitrag zum Aufbau der brasilianischen Nation. São Leopoldo, Federação dos Centros Culturais 25 de Julho, 1978, p. 401.

${ }^{7}$ Cá'sulos baseados nos dados apresentados em De Província de São Pedro a Estado do Rio Grande do Sul (Censos do RS: 1803-1950). Porto Alegre, FEE, 1986.

${ }^{8}$ Diretoria Geral de Estatística (ed.). Estatística Industrial do Rio Grande do Sul, 1937. Porto Alegre, Globo, 1939. Cabe destacar que tanto nos dados demográficos quanto nos econômicos foi omitido o munić́pio de Porto Alegre.

${ }^{9}$ Cálculos baseados nas listas de deputados apresentadas por Cabral, Oswaldo R. Breve noticia sobre o Poder Legislativo de Santa Catarina. Suas legislaturas e legisladores, 1835 a 1974. Florianópolis, Editora Lunardelli, 1974.

${ }^{10} \mathrm{Cf}$. Entres, Alberto (ed.). Guia do Estado de Santa Catarina. Florianópolis, Livraria Central, 1935.

11 bberacker, Der deutsche Beitrag ..., p. 437.

${ }^{12}$ Ramos, Nereu de Oliveira. Mensagem apresentada à Assembléia Legislativa de Santa Catarina em 16 de julho de 1936 por ... Florianópolis, Imprensa Oficial, 1936, p. 14.

${ }^{13}$ Entres, Alberto (ed.). Guia do Estado de Santa Catarina (Suplemento 1937). Florianópolis, Livraria Central, 1937.

${ }^{14}$ Relatório do consul Dittmar à embaixada alemã $\mathrm{em}$ 10.10.1934 (PA, Abt. VIA Deutschtum/Brasilien, Bd. 3).

${ }^{15}$ Silva, José Ferreira da. "História de Blumenau". In: Centenário de Blumenau (1850-1 950). Blumenau, 1950, p. 45.

${ }^{16}$ Kolonie-Zeitung (Joinville), 24.3.1936 (vertido do alemão).

* Pontifícia Universidade Católica do RGS.

Curso de Pós-Graduação em História.

90620 Porto Alegre - RS. 